\title{
Adsorption Studies on Rhodamine-B Removal from Aqueous Solution Using Acid Activated Strychnos Nux-Vomica Leaf Powder
}

\author{
S. PARTHASARATHY* ${ }^{*}$ and S ARIVOLI
}

PG and Research Department of Chemistry, Thiru Vi Ka Government Arts College, Thiruvarur - 03, Tamilnadu, India

drsaru2009@gmail.com

Received 30 June 2016 / Accepted 10 August 2016

\begin{abstract}
Acid activated strychnos nux-vomica leaf powder (SLP) was employed for removal of the rhodamine-B (RB) dye from aqueous solution. Batch adsorption studies were carried out under varying conditions of dye concentration, adsorbent dose, contact time, $\mathrm{pH}$ and temperature. Removal efficiency was $92 \%$ in $50 \mathrm{~min}$ with $6.5 \mathrm{pH}, 50 \mathrm{mg} / \mathrm{L}$ as dose, $50 \mathrm{mg} / \mathrm{L} \mathrm{RB}$ concentration and $30{ }^{\circ} \mathrm{C}$ temperature. The equilibrium data the best fitted with Langmuir model. The adsorption followed Lagergren pseudosecond order kinetics. The values of free energy change $\left(\Delta \mathrm{G}^{\circ}\right)$, enthalpy change $\left(\Delta \mathrm{H}^{\circ}\right)$ and entropy change $\left(\Delta \mathrm{S}^{\circ}\right)$ indicated the process to be spontaneous. The diffusion studies indicated that adsorption initially takes place by external mass transfer and later by intra-particle diffusion. The results indicate that SLP is a good adsorbent for the removal of RB from wastewater.
\end{abstract}

Keywords: Acid activated strychnos nux-vomica leaf powder, Adsorption, Rhodamine B, Isotherms, Kinetics, Thermodynamics

\section{Introduction}

With the revolution in textile and similar industries in Egypt, colored effluents are due to the use of organic dyes such as Methylene blue and Rhodamine-B for dying silk, cotton, leather, wool, paper and other final products. This is one of major problems concerning textile waste waters. These colored effluents have large amounts of suspended organic solids which are harmful to human beings and toxic for organisms. The removal of these dyes from wastewater has a considerable attention over the past decades to decrease their impact on the environment ${ }^{1}$. Several physical and chemical methods have been developed for the removal of organic dyes from industrial effluents. Physical methods, mainly adsorption on various supports were recognized to be a promising and effective process to remove dyes from industrial wastewater completely ${ }^{2}$. The main advantages of adsorption are the reusability of material, low-cost, ease of operation and short time of operation so it is necessary to develop effective adsorbents for the removal of dyes from textile effluents. Activated carbon is the most widely used adsorbent and can be prepared by physical activation in which carbonation 
or pyrolysis of the carbonaceous material at higher temperature $\left(500-900{ }^{\circ} \mathrm{C}\right)$ in an inert atmosphere followed by thermal activation at the same temperature in the presence of oxidizing agent such as air, steam and carbon dioxide or chemical activation in which pyrolysis and activation carried out only in one step simultaneously in presence of dehydrating agent such as $\mathrm{H}_{3} \mathrm{PO}_{4}, \mathrm{HNO}_{3}, \mathrm{KOH}, \mathrm{NaOH}, \mathrm{H}_{2} \mathrm{O}_{2}$ and $\mathrm{H}_{2} \mathrm{SO}_{4}$. Chemically activated carbon has higher yield, more surface area and better development of porous structure than that obtained by physical activation ${ }^{3}$. Several attempts have been made for the preparation of activated carbon from agriculture wastes. Water hyacinth (WH) is one of the bio-absorbent plants. $\mathrm{WH}^{4}$ propagates both by seed germination and by vegetative means where by mature plants produce rosettes of leaves and fibrous roots at each node of the growing stem. A single plant can produce about 65,000 off spring during a single season. Since WH can grow at an alarming rate, a novel activated carbon can be prepared from the dead plant. Several attempts has been described for the removal of Rhodamine-B or Methylene blue from wastewater by activated carbon prepared from agriculture wastes such as rice husk, bamboo ${ }^{5}$, rattan saw dust, yellow passion fruit, corncob hulls, sugar beet pulp $^{6}$, pineapple leaf powder, eichhornia crassipes $\operatorname{root}^{7}$, indian rose $\operatorname{wood}^{8}$, pomegranate peel $^{9}$, posidonia oceanic ${ }^{10}$.

In this paper, we report the efficiency of activated carbon prepared from strychnos nuxvomica $\mathrm{L}$ (Kanchira) $\mathrm{H}_{2} \mathrm{SO}_{4}$ activation for removal of basic dye (Rhodamine- $\mathrm{B}$ ). The isotherm, kinetic and thermodynamics of the adsorption process have been evaluated.

\section{Experimental}

All reagents used in the experiments were of analytical (AR) grade and were obtained from scientific equipment, Trichy. Stock solutions of the test reagents were prepared by dissolving the dye in distilled water.

\section{Preparation of adsorbent}

The natural plant material for strychnos nux-vomica L leaf (Figure 1) used in the present investigations was collected from a nearby Pudukkottai, Tamilnadu, India. The leaf was washed with distilled water several times to remove the dirt and dust and was subsequently dried in a hot air oven at $110{ }^{\circ} \mathrm{C}$. Afterward, carbonization of the leaves was carried out at $450{ }^{\circ} \mathrm{C}$ for $1 \mathrm{~h}$ in a muffle furnace, was maintained throughout the process of carbonization primary carbon was obtained on carbonization, which was afterward mixed with zinc chloride. Zinc chloride acts as a catalyst in the process. The primary carbon was activated at $600{ }^{\circ} \mathrm{C}$ for $6 \mathrm{~h}$ under optimized conditions to obtain activated carbon. The activated carbon was thereafter looked to room temperature in an insert atmosphere of nitrogen and washed with hot distilled water and $0.5 \mathrm{~N}$ hydrochloric acid until the $\mathrm{pH}$ of the material reached 6.5 the activated carbon was also dried in a hot air oven at $110^{\circ} \mathrm{C}$, ground and sieved to obtain the desired particular size $(150 \mu \mathrm{m})$ and stored in desiccators for further use.

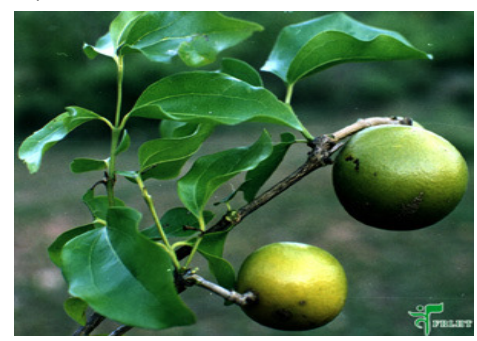

Figure 1. Plant material of strychnos nux-vomica $\mathrm{L}$ 


\section{Experimental}

Batch experiments were conducted to study the influence of important parameters like the $\mathrm{pH}$, contact time, initial dye concentration and temperature on the removal of RB onto activated SLP. For adsorption isotherms, dye solution of different concentrations $(50-250 \mathrm{mg} / \mathrm{L})$ and at different temperatures $\left(30-60{ }^{\circ} \mathrm{C}\right)$ with known $\mathrm{pH}$ and known amount of adsorbent $(1 \mathrm{~g} / \mathrm{L})$ were agitated at $207 \mathrm{rpm}$ until the equilibrium was reached then the solution was kept to settle down and the residual concentration of RB were analyzed by UV-Visible spectrophotometer at $662 \mathrm{~nm}$ and $554 \mathrm{~nm}$, respectively. All experiments were carried out at normal pH for RB. Effect of $\mathrm{pH}$ on dye removal was studied over a $\mathrm{pH}$ range of 2.2-10.4 the initial $\mathrm{pH}$ of the solution was adjusted by addition of acetate or phosphate buffers. The effect of sorbent dosage on adsorption rate was investigated at different dosages $(50-250 \mathrm{mg} / 50 \mathrm{~mL})$. The percentage of dye removal was calculated using the following equation.

$$
\mathrm{Q}_{\mathrm{t}}=\frac{\left(\mathrm{C}_{\mathrm{i}}-\mathrm{C}_{\mathrm{t}}\right) \times \mathrm{v}}{\mathrm{m}}
$$

Where $\mathrm{q}_{(\mathrm{t})}$ is the mass of adsorbed dye per unit mass of adsorbent $\left(\mathrm{mg} \mathrm{g}^{-1}\right)$ (i) and (t) are the initial and actual concentration $\left(\mathrm{g} \mathrm{dm}^{-3}\right)$ of dye at time, respectively $\mathrm{V}$ is the volume of the treated solution $(\mathrm{mL}) \mathrm{m}$ is the mass of adsorbent $(\mathrm{g})$. The adsorption degree, $\mathrm{AD}$ as a function of time was also determined from the experimental data using the following relationship

$$
\mathrm{AD} \%=\frac{\left(1-\mathrm{C}_{\mathrm{t}}\right) \times 100}{\mathrm{C}_{\mathrm{i}}}
$$

Based on the adsorption kinetics experiments, the process time for the equilibrium adsorption experiments was chosen, long enough assuming that the considered sorbent / sorbate system is equilibrated. The following parameters of the process were changed during these experiments, amount of adsorbent (Activated SLP), the particle size, initial $\mathrm{pH}$ of the solutions and the initial concentration of the considered ions, all experiments were performed at ambient temperature.

\section{Results and Discussion}

\section{Characterization}

The different chemical constituents of activated SLP are given in Table 1 along with some other characteristics. Surface area of the samples activated in air is 629 and $107 \mathrm{~m}^{2} \mathrm{~g}^{-1}$ for activated SLP, respectively. X-ray spectra of both adsorbents do not show any peak indicating the amorphous nature of activated SLP.

Table 1. Characteristics of the adsorbent

\begin{tabular}{cc}
\hline Properties & SLP \\
\hline Particle size, $\mathrm{mm}$ & 0.0190 \\
Density, g/cc & 0.2005 \\
Moisture content, \% & 0.2527 \\
Loss in ignition, \% & 0.0210 \\
pH of aqueous solution & 6.5000 \\
\hline
\end{tabular}

Table 2. Equilibrium parameters for the adsorption of RB onto SLP

\begin{tabular}{ccccccccccccc}
\hline \multirow{2}{*}{$\mathrm{M}_{0}$} & \multicolumn{4}{c}{$\mathrm{C}_{\mathrm{e}} \mathrm{mg} / \mathrm{L}$} & \multicolumn{4}{c}{$\mathrm{Q}_{\mathrm{e}}, \mathrm{mg} / \mathrm{L}$} & \multicolumn{5}{c}{ Removal \% } \\
\hline & $30{ }^{\circ} \mathrm{C}$ & $40{ }^{\circ} \mathrm{C}$ & $50{ }^{\circ} \mathrm{C}$ & $60{ }^{\circ} \mathrm{C}$ & $30{ }^{\circ} \mathrm{C}$ & $40{ }^{\circ} \mathrm{C}$ & $50{ }^{\circ} \mathrm{C}$ & $60{ }^{\circ} \mathrm{C}$ & $30{ }^{\circ} \mathrm{C}$ & $40{ }^{\circ} \mathrm{C}$ & $50{ }^{\circ} \mathrm{C}$ & $60{ }^{\circ} \mathrm{C}$ \\
\hline 50 & 3.80 & 3.63 & 3.73 & 3.00 & 92.39 & 92.72 & 92.53 & 93.98 & 92.39 & 92.72 & 92.53 & 93.98 \\
100 & 14.26 & 12.36 & 10.73 & 9.08 & 171.47 & 175.27 & 178.53 & 181.83 & 85.73 & 87.63 & 89.26 & 90.91 \\
150 & 30.36 & 27.64 & 23.09 & 20.68 & 239.26 & 244.70 & 253.80 & 258.62 & 79.75 & 81.56 & 84.60 & 86.20 \\
200 & 58.62 & 54.09 & 23.09 & 44.70 & 282.74 & 291.81 & 353.80 & 310.58 & 70.68 & 72.95 & 88.45 & 77.64 \\
250 & 90.67 & 85.68 & 49.06 & 74.68 & 318.65 & 328.62 & 401.87 & 350.63 & 63.73 & 65.72 & 80.37 & 70.12 \\
\hline
\end{tabular}




\section{Contact time}

In order to establish the equilibration time for maximum uptake and to know the kinetics of the adsorption process, Rhodamine-B adsorption on SLP adsorbent was investigated as a function of contact time and the results are shown in Figure 2 and data are given in Table 2. The figure shows that the uptake rate was initially rapid with $50 \%$ of the adsorption was completed within $45 \mathrm{~min}$, equilibrium was achieved with in $60 \mathrm{~min}$ therefore, an equilibration period of $1 \mathrm{~h}$ was selected for all further experiments. The time profile of RB uptake is a single smooth and continuous curve leading to saturation suggesting the possible monolayer coverage of RB on the surface of the adsorbent.

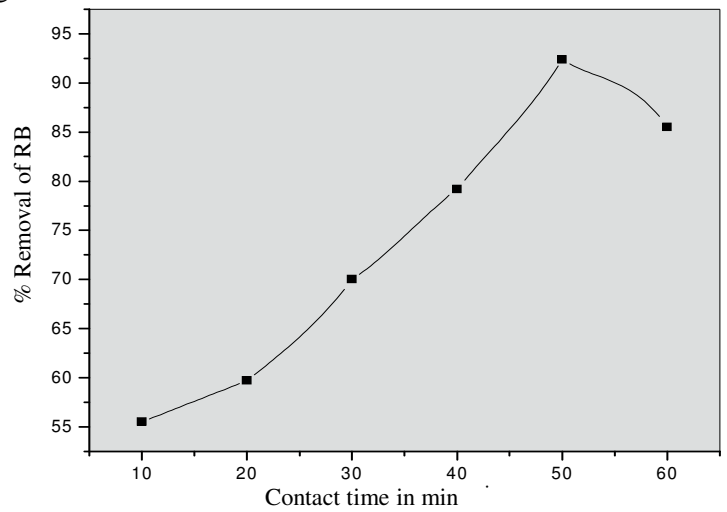

Figure 2. Effect of contact time on the removal of $\mathrm{RB}[\mathrm{RB}]=50 \mathrm{mg} / \mathrm{L}$; temperature $30{ }^{\circ} \mathrm{C}$; adsorbent dose $=50 \mathrm{mg} / 50 \mathrm{~mL}$

\section{Effect of adsorbent dosage}

The adsorption of the Rhodamine-B dye on SLP was studied by varying the adsorbent dose $(50-250 \mathrm{mg} / 50 \mathrm{~mL})$ for $50 \mathrm{mg} / \mathrm{L}$ of dye concentration. The percentage of adsorption increased with increases in the SLP concentration, which is attributed to increased carbon surface area and the availability of more adsorption sites ${ }^{11}$. Hence, all studies were carried out with $0.050 \mathrm{~g}$ of adsorbent $/ 50 \mathrm{~mL}$ of the varying adsorbate solutions $50,100,150,200$ and $250 \mathrm{~mL}$. The results obtained from this study are shown in Figure 3. The amount of RB adsorbed per gram reduced with increase in the dosage of SLP. This reveals that the direct and equilibrium capacities of RB are functions of the activated SLP dosage.

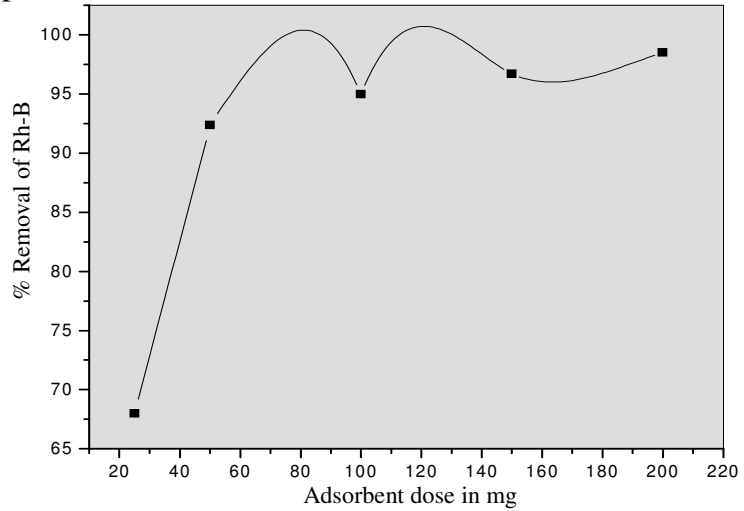

Figure 3. Effect of adsorbent dose on the removal of RB $[R B]=50 \mathrm{mg} / \mathrm{L}$; contact time $60{ }^{\circ} \mathrm{C}$; temperature $30{ }^{\circ} \mathrm{C}$ 


\section{Effect of initial $\mathrm{pH}$}

Previous research has shown that the adsorption of dye molecules onto an adsorbent is highly $\mathrm{pH}$ dependent since the functional groups, which are responsible for interaction between dye molecules and adsorbent, can be protonated or deprotonated to produce different surface charges in solution at different $\mathrm{pH}$ values ${ }^{12}$. Therefore the effects of initial solution $\mathrm{pH}$ were studied in the $\mathrm{pH}$ range of 2-10 for $\mathrm{RB}$. The percentage removal increased from $63 \%$ to $94 \%$ for RB where as it decreased slowly after $\mathrm{pH} 8$ for RB (Figure 4). The $\mathrm{pH}_{\mathrm{PZC}}$ of any adsorbent is a very important characteristic that determines the $\mathrm{pH}$ at which the surface has net electrical neutrality. It is well-known that for basic dye adsorption, negatively charged groups on the adsorbent are necessary. At lower $\mathrm{pH}$ values $\left(\mathrm{pH}<\mathrm{pH}_{\mathrm{PZC}}\right)$ the surface charge of the surface of SLP may get positively charged as a result of being surrounded by $\mathrm{H}_{3} \mathrm{O}^{+}$ions and thus the competitive effects of $\mathrm{H}_{3} \mathrm{O}^{+}$ions as well as the electrostatic repulsion between the dye molecules and the positively charged active adsorption sites on the surface of the SLP lead to a decrease in the uptake of dye molecules. In contrast at higher $\mathrm{pH}$ values $\left(\mathrm{pH}>\mathrm{pH}_{\mathrm{PZC}}\right)$ the surface of SLP may acquire a negative charge leading to an increase in dye uptake due to the electrostatic force of attraction. On the other hand no valid reason can be given for the decrease in the adsorption amount of RB after $\mathrm{pH}$ 8. Similar results were obtained for the adsorption of Rhodamine-B onto activated SLP. As a result, the initial $\mathrm{pH}$ value was optimized as 6.5 for dye.

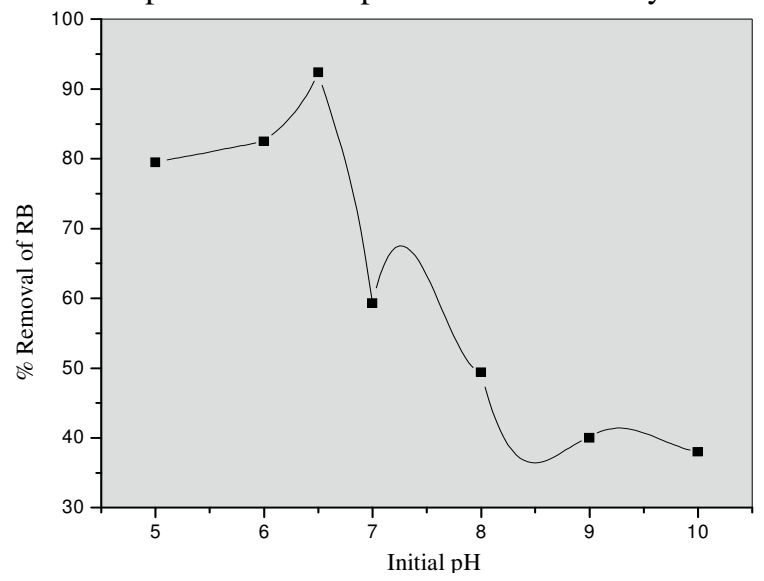

Figure 4. Effect of initial $\mathrm{pH}$ on the removal of $\mathrm{RB}[\mathrm{RB}]=50 \mathrm{mg} / \mathrm{L}$; temperature $30^{\circ} \mathrm{C}$; adsorbent dose $=50 \mathrm{mg} / 50 \mathrm{~mL}$

\section{Kinetic modeling in a batch system}

In order to investigate the mechanism of adsorption kinetic models are generally used to test experimental data. Pseudo-first-order and pseudo-second-order equations can be used assuming that the measured concentrations are equal to surface concentrations ${ }^{13}$. The pseudo-first-order rate lagergren model is ${ }^{14}$ :

$$
\frac{\mathrm{dq}}{\mathrm{dt}}=\mathrm{k}_{1} \text {, ads }\left(\mathrm{q}_{\mathrm{e}}-\mathrm{q}\right)
$$

Where, $\mathrm{q}(\mathrm{mg} / \mathrm{g})$ is the amount of adsorbed heavy metals on the adsorbent at time $\mathrm{t}$ and $\mathrm{k}_{1}$,ads $\left(\mathrm{min}^{-1}\right)$ is the rate constant of first-order adsorption ${ }^{15}$. The integrated form of Eq. 3 is:

$$
\log \left(\mathrm{q}_{\mathrm{e}}-\mathrm{q}\right)=\log \mathrm{q}_{\mathrm{e}}{ }^{-} \frac{\mathrm{k}_{1} \text {,ads }}{2.303} \mathrm{t}
$$


$\mathrm{q}_{\mathrm{e}}$ the equilibrium sorption uptake, is extrapolated from the experimental data at time $\mathrm{t}=$ infinity. A straight line of $\log \left(\mathrm{q}_{\mathrm{e}}-\mathrm{q}\right)$ versus $\mathrm{t}$ suggests the applicability of this kinetic model. $\mathrm{q}_{\mathrm{e}}$ and $\mathrm{k}_{1}$, ads can be determined from the intercept and slope of the plot, respectively. The pseudo-second order kinetic model is expressed as ${ }^{16}$ :

$$
\frac{\mathrm{dq}}{\mathrm{dt}}=\mathrm{k}_{2}, \operatorname{ads}\left(\mathrm{q}_{\mathrm{e}}-\mathrm{q}\right)^{2}
$$

Where, $\mathrm{k}_{2}$,ads $(\mathrm{g} / \mathrm{mg} \mathrm{min})$ is the rate constant of second-order adsorption. The integrated form of Eq. 5 is:

$$
\frac{\mathrm{dq}}{\mathrm{q}_{\mathrm{e}}-\mathrm{q}}=\frac{1}{\mathrm{q}_{\mathrm{e}}} \mathrm{k}_{2} \text {,ads } \mathrm{t}
$$

Eq. 6 can be rearranged and linearized to obtain:

$$
\frac{\mathrm{t}}{\mathrm{q}}=\frac{1}{\mathrm{k}_{2}, \operatorname{adsq}_{\mathrm{e}}{ }^{2}}+\frac{1}{\mathrm{q}_{\mathrm{e}}} \mathrm{t}
$$

The plot $\mathrm{t} / \mathrm{q}$ versus $\mathrm{t}$ should give a straight line if second order kinetic model is applicable and $\mathrm{q}_{\mathrm{e}}$ and $\mathrm{k}_{2, \text { ads }}$ can be determined from the slope and intercept of the plot, respectively. It is important to notice that for the application of this model the experimental estimation of $\mathrm{q}_{\mathrm{e}}$ is not necessary ${ }^{17,18}$. Data is given in Table 5

\section{Weber and Morris intra-particle diffusion model}

Kinetic data was further analyzed using the intraparticle diffusion model based on the theory proposed by Weber and Morris ${ }^{19}$. The amount of RB adsorbed $\left(q_{t}\right)$ at time ' $t$ ' was plotted against the square root of time $\left(\mathrm{t}^{1 / 2}\right)$, according to Eq. 8 .

$$
\mathrm{Q}_{\mathrm{t}}=\mathrm{k}_{\mathrm{id}} \mathrm{t}^{1 / 2}+\mathrm{C}
$$

Where $\mathrm{k}_{\mathrm{id}}$ is the intraparticle diffusion rate constant and $\mathrm{c}$ is the intercept related to the thickness of the boundary layer. According to above equation a plot of $\mathrm{q}_{\mathrm{t}}$ versus $\mathrm{t}^{1 / 2}$ should be a straight line from the origin if the adsorption mechanism follows the intraparticle diffusion process only ${ }^{20}$. However, if the data exhibit multi linear plots, then the process are governed by two or more steps, It is clear from that there are two separate cases: first linear portion (phase I) and second linear part (phase II). The first linear portion (Phasse I) can be attributed to the immediate utilization of the most readily available adsorbing sites on the adsorbent surface, phase II may be attributed to very slow diffusion of the adsorbate from the surface site in to the inner pores. Thus initial portion of RB adsorption by adsorbent may be governed by the initial intraparticle transport of RB controlled by surface diffusion process and the later part controlled by pore diffusion. However, the intercept of the line fails to pass through the origin which may be due to the difference in the rate of mass transfer in the initial and final stages of adsorption. Further, such deviation of the straight lines from the origin reveals that the pore diffusion is not the sole rate controlling ${ }^{20}$.

\section{Adsorption isotherms}

In order to determine the adsorption efficacy of activated SLP adsorbent for RB adsorption, the equilibrium adsorption studies were carried out at room temperature $\left(30^{\circ} \mathrm{C}\right)$ that the other initially raises sharply, indicating that plenty of readily accessible sites are available in the beginning for adsorption. However after equilibration when the adsorbent becomes saturated, a plateau is reached indicating that no more sites are available for further adsorption an adsorption capacity was observed for RB on activated SLP adsorbent at $30^{\circ} \mathrm{C}$. Adsorption potential of activated SLP adsorbent from the present study was compared with other adsorbent reported in previous studies for RB removal and compiled. It is seen that the prepared adsorbent in the present study shows lower adsorption capacity for RB removal 
compared to some previously developed adsorbents. This might be due to difference in experimental conditions. Research is being focused now to enhance the adsorption potential of prepared adsorbent by surface modification.

\section{Adsorption models}

The adsorption equilibrium data were further analyzed into two well known isotherm models via Freundlich and Langmuir models.

\section{Freundlich model}

The Freundlich model which is an indicative of surface heterogeneity of the adsorbent is described by the following equation ${ }^{21}$.

$$
\log \mathrm{q}_{\mathrm{e}}=\log \mathrm{k}_{\mathrm{f}}+1 / \mathrm{n}+\log \mathrm{C}_{\mathrm{e}}
$$

Where $\mathrm{k}_{\mathrm{f}}$ and $1 / \mathrm{n}$ are Freundlich constants associated with adsorption capacity and adsorption intensity respectively, The Freundlich plots between $\log q_{e}$ and $\log C_{e}$ for the adsorption of RB were drawn. It was found that correlation efficient values were less than 0.99 at both the temperature studied indicating that Freundlich model was not applicable to this study.

\section{Langmuir model}

The adsorption isotherm was also fitted to Langmuir model ${ }^{22}$. The Langmuir equation which is valid for monolayer adsorption on to a surface is given below.

$$
1 / q_{\mathrm{e}}=1 / \mathrm{q}_{\mathrm{m}}+1 / \mathrm{q}_{\mathrm{m}} \mathrm{bC} \text { e }
$$

Where $\mathrm{q}_{\mathrm{e}}\left(\mathrm{mg} \mathrm{g}^{-1}\right)$ is the amount adsorbed at the equilibrium concentration $\mathrm{C}_{\mathrm{e}}\left(\mathrm{mol} \mathrm{L}^{-1}\right)$, $\mathrm{q}_{\mathrm{m}}\left(\mathrm{mgg}^{-1}\right)$ is the Langmuir constant representing the maximum monolayer adsorption capacity and $b\left(\mathrm{~L} \mathrm{~mol}^{-1}\right)$ is the Langmuir constant related to energy of adsorption. The plots $1 / \mathrm{q}_{\mathrm{e}}$ as a function of $1 / \mathrm{C}_{\mathrm{e}}$ for the adsorption of $\mathrm{RB}$ was found linear. Suggesting the applicability if Langmuir model in the present adsorption system. The correction coefficient $\left(\mathrm{R}^{2}=0.9926\right.$ and 0.9932 at 30 and $60{ }^{\circ} \mathrm{C}$ respectively for Langmuir model) confirm good agreement between both theoretical models and our experimental results the values of the monolayer capacity $\left(\mathrm{q}_{\mathrm{m}}\right)$ and equilibrium constant $(\mathrm{b})$ have been evaluated from the intercept and slope of these plots and given in Table 3. It is adsorbent for the RB is comparable to the maximum adsorption obtained from the adsorption isotherms. These facts suggest that RB is adsorbed in the form of monolayer coverage on the surface of the prepared adsorbent. Satisfactory fitting of the Langmuir model to the adsorption of RB on activated SLP adsorbents has also been reported by various researchers ${ }^{23}$.

Table 3. Langmuir and Freundlich isotherm parameter for the adsorption of RB onto SLP

\begin{tabular}{ccccc}
\hline Temp. ${ }^{\circ} \mathrm{C}$ & \multicolumn{2}{c}{ Langmuir parameters } & \multicolumn{2}{c}{ Freundlich parameters } \\
\cline { 2 - 5 } & $\mathrm{Q}_{\mathrm{m}}$ & $\mathrm{b}$ & $\mathrm{K}_{\mathrm{f}}$ & $\mathrm{n}$ \\
\hline 30 & 361.73 & 0.0703 & 1.7603 & 2.5411 \\
40 & 373.39 & 0.0753 & 1.7743 & 2.4949 \\
50 & 574.08 & 0.0464 & 1.6440 & 1.6932 \\
60 & 395.68 & 0.0940 & 1.8278 & 2.4673 \\
\hline
\end{tabular}

\section{Thermodynamic studies}

Thermodynamic parameters related to the adsorption process, i.e., Gibb's free energy change $\left(\Delta \mathrm{G}^{0}, \mathrm{~J} \mathrm{~mol}^{-1}\right)$, enthalpy change $\left(\Delta \mathrm{H}^{0}, \mathrm{kJmol}^{-1}\right)$ and entropy change $\left(\Delta \mathrm{S}^{0}, \mathrm{Jmol}^{-1} \mathrm{~K}^{-1}\right)$ are determined by the following equations:

$$
\begin{aligned}
\Delta G^{0} & =\Delta H^{0}-T \Delta S^{0} \\
\Delta G^{0} & =-R T \ln \left(K_{c}\right)
\end{aligned}
$$


Where, $\mathrm{R}$ is the universal gas constant $\left(8.314 \mathrm{JK}^{-1} \mathrm{~mol}^{-1}\right), \mathrm{T}$ is the absolute temperature (Kelvin) and $\mathrm{K}$ represents the equilibrium adsorption constants of the isotherm fits $\left(\mathrm{K}_{\mathrm{L}}\right.$, Langmuir equilibrium constant and $\mathrm{K}_{\mathrm{f}}$, Freundlich equilibrium constant, which must be converted to SI units, by using the molecular mass of the RB dye) obtained from the isotherm plots. $\Delta \mathrm{H}^{\circ}$ and $\Delta \mathrm{S}^{\circ}$ values can be calculated from the slope and intercept of the linear plot of $\ln (\mathrm{K})$ versus $1 / \mathrm{T}$. Thermodynamic results are depicted in Table 4 . Enthalpy changes $\left(\Delta \mathrm{H}^{\circ}\right)$ indicate that adsorption followed endothermic processes. Negative values of $\Delta \mathrm{G}^{\mathrm{o}}$ indicate that the methylene blue dye adsorption by the adsorbent is spontaneous and favorable processes for all studied temperatures. The positive values of $\Delta S^{0}$ confirm a high preference of methylene blue molecules for the carbon surface of adsorbent and also suggest the possibility of some structural changes or readjustments in the dye-carbon adsorption complex. Besides, it is consistent with the dehydration of dye molecule before its adsorption to carbon surface, and the releases water molecules to the bulk solution. The increase in the adsorption capacities of adsorbent at higher temperatures may be attributed to the enhanced mobility and penetration of dye molecules within the adsorbent porous structures by overcoming the activation energy barrier and enhancing the rate of intra-particle diffusion ${ }^{24}$.

Table 4. Thermodynamic parameter for the adsorption of RB onto SLP

\begin{tabular}{|c|c|c|c|c|c|c|}
\hline \multirow{2}{*}{$\mathrm{C}_{0}$} & \multicolumn{4}{|c|}{$\Delta \mathrm{G}^{\mathrm{o}}, \mathrm{J} \mathrm{mol}^{-1}$} & \multirow{2}{*}{$\begin{array}{c}\Delta \mathrm{H}^{\circ} \\
\mathrm{kI} \mathrm{mol}^{-1}\end{array}$} & \multirow{2}{*}{$\begin{array}{c}\Delta \mathrm{S}^{\circ} \\
\mathrm{Imol}^{-1} \mathrm{~K}^{-1}\end{array}$} \\
\hline & $30^{\circ} \mathrm{C}$ & $40^{\circ} \mathrm{C}$ & $50^{\circ} \mathrm{C}$ & $60^{\circ} \mathrm{C}$ & & \\
\hline 50 & -6289.62 & -6623.7 & -6759.89 & -7612.5 & 6.029 & 40.41 \\
\hline 100 & -4518.22 & -5096.11 & -5689.3 & -6377.31 & 14.15 & 61.56 \\
\hline 150 & -3453.76 & -3870.54 & -4575.28 & -5074.15 & 13.42 & 55.54 \\
\hline 200 & -2217.31 & -2582.12 & -5467.31 & -3447.26 & 18.39 & 68.61 \\
\hline 250 & -1420.07 & -1694.32 & -3786.12 & -2362.47 & 13.97 & 51.23 \\
\hline
\end{tabular}

Table 5. The kinetic parameters for adsorption for the adsorption of RB onto SLP

\begin{tabular}{|c|c|c|c|c|c|c|c|c|c|c|c|}
\hline \multirow{2}{*}{ i } & \multirow{2}{*}{ 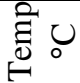 } & \multicolumn{4}{|c|}{ Pseudo second order } & \multicolumn{3}{|c|}{ Elovich model } & \multicolumn{3}{|c|}{ Intraparticle diffusion } \\
\hline & & $\mathrm{q}_{\mathrm{e}}$ & $\mathrm{k}_{2}$ & $\gamma$ & $\mathrm{h}$ & $\alpha$ & $\beta$ & $\gamma$ & $\overline{\mathrm{K}_{\mathrm{id}}}$ & $\gamma$ & $\mathrm{C}$ \\
\hline \multirow{4}{*}{50} & 30 & 102.15 & & 9952 & 4.01 & 134.90 & 0694 & 9959 & 6 & 0.994 & 1771 \\
\hline & 40 & .41 & & 83 & 16.28 & 67 & 6 & 58 & $1 . / 065$ & 95 & 416 \\
\hline & 50 & & & 9960 & 17.75 & 47 & 13 & 0 & 1. & 0.991 & 0.1298 \\
\hline & 60 & 59 & & 940 & 17.50 & 61 & 8 & & & 0.999 & 0.1446 \\
\hline \multirow{4}{*}{100} & 30 & 7 & & 946 & 26.66 & 297.98 & & 61 & & 0.998 & 705 \\
\hline & 40 & 192.25 & $24 \times 10^{-3}$ & .9988 & 27.23 & 353.65 & 0.0 & 0.9987 & & 0.997 & 0.1647 \\
\hline & 50 & & -3 & & 29 & & & & & 0.994 & 0.1590 \\
\hline & 60 & & & & 32 & 4 & & 9 & 1. & 0.9 & 62 \\
\hline \multirow{4}{*}{150} & 30 & & & & 33 & & & & & 0.997 & 312 \\
\hline & 40 & 26 & & 67 & 38.25 & 92 & $0 .($ & 0.9967 & & 0.999 & 718 \\
\hline & 50 & 278.59 & $26 \times 10^{-3}$ & 0.9961 & 40.42 & 500.05 & 0.0267 & 0.9983 & 1.6 & 0.998 & 0.1662 \\
\hline & 60 & & $24 \times 10^{-3}$ & 0.9981 & 34.63 & 673.53 & 0.0 & 0.9943 & 1.6 & 0.997 & 520 \\
\hline \multirow{4}{*}{200} & 30 & & & & & & & & & & 79 \\
\hline & 40 & 80 & & & 38 & 27 & & & & 0.992 & 46 \\
\hline & 50 & 33 & )$^{-3}$ & 73 & 39.6 & 267 & & 0. & & 0.994 & 973 \\
\hline & 60 & & & & 44 & & & & & 0.991 & 830 \\
\hline \multirow{4}{*}{250} & 30 & 4.90 & & 928 & 35.93 & 168.18 & 0.0 & 0.9948 & 1.3 & 0.992 & 0.2255 \\
\hline & 40 & 377.59 & $32 \times 10^{-3}$ & 0.9941 & 36.36 & 164.50 & 0.0 & 0.9994 & 1.4028 & 0.991 & 0.2288 \\
\hline & 50 & & & & 37. & 174.85 & & 0.9 & & 0.992 & 0.2264 \\
\hline & 60 & 397.03 & $31 \times 10^{-3}$ & 0.9959 & 42.08 & 228.70 & 0.0156 & 0.9963 & 1.4589 & 0.991 & 0.2129 \\
\hline
\end{tabular}




\section{Desorption studies}

In order to assess the reusability of RB-loaded activated SLP biomass desorption experiments were carried out. The effect of strength of desorbing solution $(\mathrm{NaOH})$ on the recovery of RB is shown in Figure 5. It is evident from the above figure that when the strength of the desorbing solution increased from 0.5 to $2.0 \mathrm{M}, \mathrm{RB}$ desorption percentage increased from $30 \%$ to $85 \%$. Thus a significant amount of Rhodamine-B is being desorbed, which shows that the SLP biomass can be effectively reused after desorption ${ }^{25}$.

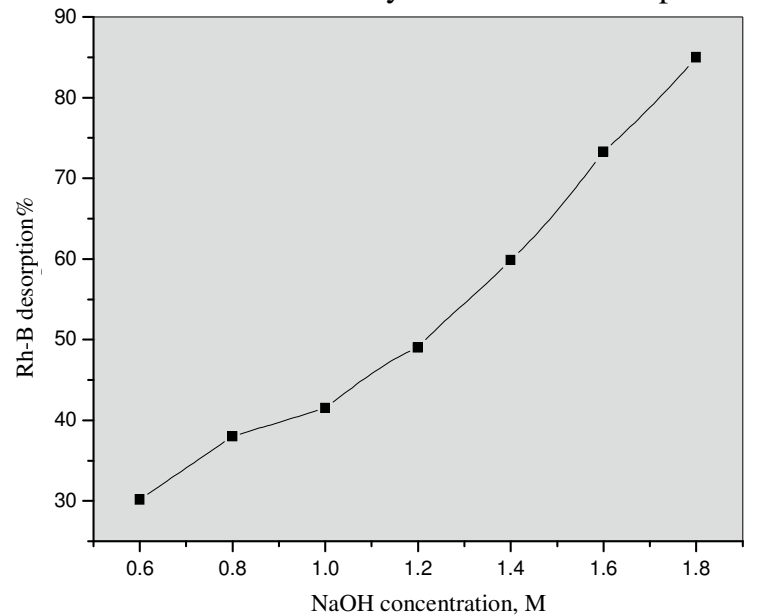

Figure 5. Effect of $\mathrm{NaOH}$ concentration of Rhodamine-B desorption

\section{Conclusion}

The composite adsorbent exhibited effectiveness in the removal of RB dye from aqueous solution. The removal efficiency was controlled by solution $\mathrm{pH}$, adsorbent concentration, contact times and initial dye concentration. Adsorption data fitted well with the Langmuir and Freundlich models however, Langmuir isotherm displayed a better fitting model than Freundlich isotherm because of the higher correlation coefficient that the former exhibited, thus, indicating to the applicability of monolayer coverage of the Langmuir dye on the surface of adsorbent. Strychnos nux-vomica L leaf to produce activated carbons potentially provide a less expensive raw material, a highly effective adsorbent as well as production of activated carbon processed from renewable resources instead of non-renewable ones.

\section{Reference}

1. Damirchi S, Ghafourian H and Malekian F, Cumhuriyet Sci J., 2015, 36(6).

2. Muthukumaran K and Sophie B, Procedia Environ Sci., 2011, 4, 266-280; DOI:10.1016/j.proenv.2011.03.032

3. Selomulya C, Meeyoo V and Amal R, J Chem Technol Biotechnol., 1999, 74(2), 111122; DOI:10.1002/(SICI)1097-4660(199902)74:2<111::AID-JCTB990>3.0.CO;2-D

4. $\quad$ Eswari B, Amala Dr and Poonguzhali T V, Inter J Adv Res., 2015, 3(10), 547-553.

5. Gholipour M, Hashemipour $\mathrm{H}$ and Mollashahi M, ARPN J Engg Appl Sci., 2011, 6(9), 10-18.

6. Souundarrajan M, Gomathi T and Sudha P N, Arch Appl Sci Res., 2012, 4(1), 225-235.

7. Sivakumar R, Arivoli S and V Marimuthu V, Int J Environ, Agri Biotechnol., 2017, 2(1), 30-39. DOI: 10.22161/ijeab/2.1.6 
8. Mekonnen E, Yitbarek M and Refera Soreta T, South Afr J Chem., 2015, 68, 45-52; DOI:10.17159/0379-4350/2015/v68a7

9. Esmaeili A, Ghasemi S and Rustaiyan A, J Marine Sci Technol., 2010, 18(4), 587-592.

10. Chen S, Yue Q, Gao B, Li Q, Xu X and Fu K., Bioresource Technol., 2012, 113, 114-120; DOI:10.1016/j.biortech.2011.11.110

11. Gupta S and Babu B V, J Water Resource Protection, 2010, 2, 706-716; DOI:10.4236/jwarp.2010.28081

12. Sivamani S and Prince V, J Environ Sci Engg., 2008, 50(1), 11-16.

13. Srinivasan $\mathrm{K}$ and Sathiya E, E J Chem., 2009, 6(4), 1167-1175; DOI: $10.1155 / 2009 / 106127$

14. Geetha A, Sivakumar P, Sujatha M and Palanisamy P N, J Environ Sci Engg., 2009, 51(2), 151-156.

15. Hema M and Arivoli S, Indian J Chem Technol., 2009, 16(1), 38.

16. Singha B and Das S K, Coll Surf B: Biointer., 2011, 84(1), 221-232; DOI:10.1016/j.colsurfb.2011.01.004

17. Ghosh P K, J Hazard Mater., 2009, 171(1-3), 116-122;

DOI:10.1016/j.jhazmat.2009.05.121

18. Singh K K, Hasan S H, Talat M, Singh V K and Gangwar S K, Chem Eng J., 2009, 151(1-3), 113-121; DOI:10.1016/j.cej.2009.02.003

19. Walter J Weber and J Carrell Morris, J Sanitary Engineering Division, 1963, 89(2), 31-60.

20. Gonul D and Zumriye A, Process Biochem., 2002, 38(5), 751-762; DOI:10.1016/S0032-9592(02)00204-2

21. Pereira M R, Arroya P A, Dornellas de Barros M A, Sanches V M, da Silva E A, Fonseca I M and Lovera R G, Adsorption, 2006, 12(2), 155-162; DOI:10.1007/s10450-006-0377-Z

22. Wang X S, Tang Y P and Tao S R, Adsorption, 2008, 14(6), 823; DOI:10.1007/s10450-008-9145-6

23. Bulgariu L, Robu B and Macoveanu M, Rev Chim., 2009, 60, 177.

24. Guo X, Zhang S and Shan X, J Hazard Mater., 2008, 151(1), 134-142; DOI:10.1016/j.jhazmat.2007.05.065

25. Arivoli S, Marimuthu V and Mohamed Jahangir A R, Int J Bioassays, 2015, 4(1), 3611-3617. 